\title{
Comparison of preoxygenation efficiency with intersurgical economy and intersurgical quadralite anaesthetic face masks
}

\author{
Eglè Kontrimavičiūtè $\dot{1}^{1,2 *}$, Rūta Janulevičienè ${ }^{1}$, Greta Sakalauskaite் $\dot{~}^{3}$, Evaldas Kauzonas and Greta Bukelyté $^{3}$ \\ ${ }^{1}$ Center of Anaesthesiology, Intensive Care and Pain Treatment of Vilnius University Hospital Santaros Clinics, Vilnius, Lithuania \\ ${ }^{2}$ Clinic of Anaesthesiology and Intensive Care, Institute of Clinical Medicine, Faculty of Medicine, Vilnius University, Vilnius, Lithuania \\ ${ }^{3}$ Faculty of Medicine, Vilnius University, Lithuania
}

\begin{abstract}
Background: Sufficient preoxygenation prevents arterial oxygen desaturation prior to intubation. An optimally sealed facemask is necessary for fast preoxygenation. Aim: to compare the efficiency of preoxygenation using two different facemasks.

Materials and methods: In 2018 a prospective study was conducted. Patients were classified into groups: Group A - Intersurgical Economy facemasks, Group B Intersurgical QuadraLite masks. The circuit was flushed with $100 \% \mathrm{O}_{2}$ for 30 s, preoxygenation started with flow of $81 / \mathrm{min}, \mathrm{FiO}, 100$. Patients were asked to breathe deeply. Fentanyl $(1-2 \mathrm{mcg} / \mathrm{kg})$ was administered to increase mask toleration. End-tidal oxygen concentration $\left(\mathrm{EtO}_{2}\right) \geq 90 \%$ was the goal. EtO $\mathrm{O}_{2}$ was monitored after 30, 60, 90, 120, 180, 210, 240, 270 and 300 seconds. Data analyzed using Independent-Samples T-test, Mann-Whitney-U test.

Results: 12 patients were enrolled in group A and 19 in group B. Differences in gender, age, BMI and Mallampati class in the groups were statistically insignificant $(\mathrm{p}=0.13,0.39,0.65,0.43$ respectively). Patients assigned to ASA I - 25.8\% ( $n=8->2 / 6)$, ASA II $-71.0 \%(n=22->10 / 12)$, ASA III- 3.2\% ( $n=1->0 / 1)$, p=0.64. The success rate of preoxygenation to $\mathrm{EtO}_{2} 90$ within 5 min was statistically significantly different in the groups with $33.3 \%$ in group $\mathrm{A}$ and $94.7 \%$ in group $\mathrm{B}$ ( $\mathrm{p}<0.01$ ). Mean time to $\mathrm{EtO}_{2} 90$ was $228.3 \pm 104.0 / 164.4 \pm 84.3$. Mean $\mathrm{EtO}_{2}$ after: $30 \mathrm{~s}-56.0 \pm 13.5 / 69.3 \pm 11.2(\mathrm{p}<0.01)$; 60s- 63.8 $\pm 15.3 / 76.1 \pm 11.7$ (p=0.02), 90s- 67.8 $\pm 17.7 / 80.7 \pm 10.1(\mathrm{p}=0.03) ; 120 \mathrm{~s}-69.6 \pm 18.2 / 83.4 \pm 10.0(\mathrm{p}=0.03), 150 \mathrm{~s}-71.1 \pm 19.0 / 87.1 \pm 6.5(\mathrm{p}=0.01) ; 180 \mathrm{~s}-72.9 \pm 16.8 / 88.5 \pm 5.3(\mathrm{p}=0.01), 210 \mathrm{~s}-72.6 \pm$ 18.0/89.2 \pm 5.1 ( $\mathrm{p}<0.01) ; 240 \mathrm{~s}-74.17 \pm 15.4 / 90.0 \pm 4.3$ (p<0.01), 270s-76.3 $\pm 16.3 / 90.2 \pm 3.6 ; 300 \mathrm{~s}-77.8 \pm 14.6 / 90.2 \pm 1.5$ (p<0.01).
\end{abstract}

Conclusions: Preoxygenation was significantly more efficient and faster with Intersurgical QuadraLite facemasks.

\section{Introduction}

Preoxygenation, also known as denitrogenation, is a routine procedure performed prior to the induction of general anaesthesia. Room air is replaced with oxygen and its reservoir in the lungs is created [1]. Proper preoxygenation prolongs safe apnea time during airway instrumentation and also helps to avoid arterial desaturation if unanticipated difficult airway is encountered [2]. It is well established that arterial desaturation is the risk factor of arrhythmia, hemodynamic decompensation, hypoxic brain injury, and also death [3].

Sufficient preoxygenation is defined as reaching the endtidal oxygen $\left(\mathrm{EtO}_{2}\right)$ concentration of $\geq 90 \%[4,5]$. An indicator of incomplete preoxygenation is $\mathrm{EtO}_{2}$ lower than $90 \%$ at the functional residual capacity level. 3 to 5 minutes of breathing $100 \%$ oxygen or 8 deep breaths within $1 \mathrm{~min}$ is thought to be sufficient to reach $90 \%$ of $\mathrm{EtO}_{2}[6]$.

Ineffective face mask seal is the most common cause of insufficient preoxygenation [7]. An optimally sealed facemask that prevents entrainment of operating room air into the circuit and leaks is necessary for fast and efficient preoxygenation [8].

A new type of anaesthesia face mask (QuadraLite, produced by Intersurgical) has recently been introduced, which in contrast to the regular face mask, has a soft edge instead of an air-filled cushion. The new face mask is comfortable for patients and is said to provide a superior seal in a variety of different face anatomy [9]. Therefore, we conducted a prospective randomised study to compare preoxygenation efficiency using the regular anaesthesia face mask with air-filled cushion and the new type anaesthesia face mask.

\section{Materials and Methods}

A prospective study was conducted at Vilnius University Hospital Santaros Clinics in July - August, 2018. Permission from the institutional bioethics committee was obtained and every subject consented to participate.

The study subjects were patients undergoing general anaesthesia for elective surgery. Subject exclusion criteria were as follows: pulmonary comorbidities; modified Mallampati score III (soft palate and base of uvula visible) - IV (only hard palate visible); potentially compromised mask seal ( $\geq 2$ of the following: missing teeth, snoring, bearded, obese) $[5,10]$. Prior to anaesthesia, subjects were randomly

*Correspondence to: Eglè Kontrimavičiūtè, Center of Anaesthesiology, Intensive Care and Pain Treatment of Vilnius University Hospital Santaros Clinics, Vilnius, Lithuania, Santariškių g. 2, Vilnius, Lithuania, Tel: +37067523513; E-mail: egle. kontrimaviciute@santa.lt

Keywords: preoxygenation, facemask, oxygen

Received: February 20, 2019; Accepted: March 01, 2019; Published: March 05, 2019 
assigned to two groups according to the mask to be used. Group A - Economy anaesthetic face mask; group B - QuadraLite anaesthetic face mask, both produced by Intersurgical Ltd., UK. Appropriate mask size was chosen based on manufacturer instructions [9,11]. GE Avance cS2 anaesthesia machines equipped with Datex-Ohmeda differential paramagnetic sensor were used for gas measurement.

The operating room table was set at $10^{\circ}$ reverse Trendelenburg position for preoxygenation. After flushing the breathing circuit with $100 \% \mathrm{O}_{2}$ for 30 seconds, patient preoxygenation was initiated with $\mathrm{FiO}_{2} 100 \%$ at $8 \mathrm{~L} / \mathrm{min}$. All the subjects were preoxygenated by a single anaesthesiologist using EC clamp face mask holding technique. Patients were instructed to breathe long, deep breaths. Meanwhile, 1-2 mcg/ $\mathrm{kg}$ of fentanyl was administered to increase mask toleration. End-tidal oxygen concentration $\left(\mathrm{EtO}_{2}\right)$ was recorded every 30 seconds for a total of 5 minutes of preoxygenation. $\mathrm{EtO}_{2} \geq 90 \%$ was set as the benchmark for optimal preoxygenation. In cases of suboptimal preoxygenation during the 5 minutes, additional maneuvers were employed to achieve optimal $\mathrm{EtO}_{2}$ values in order to prevent any potential harm to the patient.

Subject sex, age, body mass index (BMI), Mallampati score and ASA class were also collected. Statistical analysis was performed in IBM SPSS Statistics 25.0. Demographic data were analysed using Fisher's exact test due to small sample size. The independent-samples T test and Mann-Whitney $\mathrm{U}$ test were used to compare $\mathrm{EtO}_{2}$ values between groups.

\section{Results}

A total of 31 patients were enrolled in the study. 12 patients were assigned to group A and 19 to group B. There were no statistically

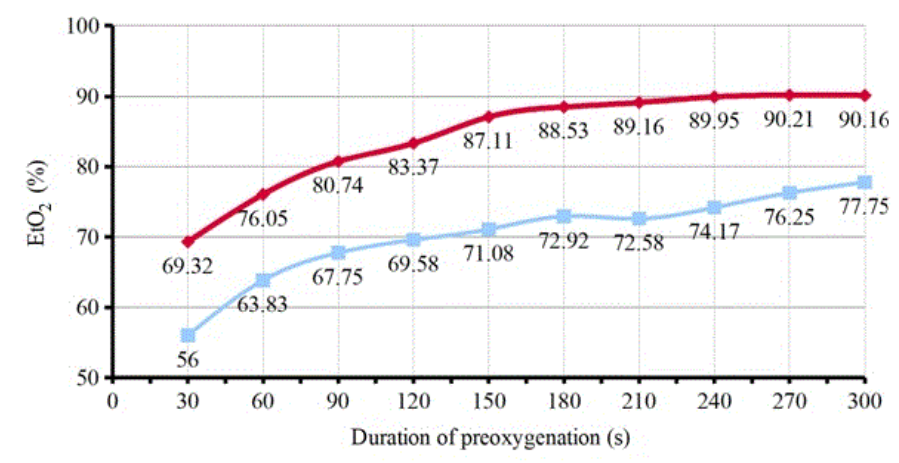

- - Intersurgical Economy (Group A)

—IntersurgicalQuadraLite (Group B)

* Difference statistically significant at each 30 s interval $(\mathrm{P}<0,05)$

Figure 1. Comparison of $\mathrm{EtO}_{2}$ at different duration of preoxygenation*

Table 1. Comparison of demographic data

\begin{tabular}{|c|c|c|c|c|}
\hline \multirow{2}{*}{ Sex } & Male & $\begin{array}{c}\text { Intersurgical } \\
\text { Economy }\end{array}$ & $\begin{array}{c}\text { Intersurgical } \\
\text { QuadraLite }\end{array}$ & \multirow{2}{*}{ P } \\
\cline { 1 - 4 } Age & Female & $50 \%(\mathrm{n}=6)$ & $21.1 \%(\mathrm{n}=4)$ & \multirow{2}{*}{0.127} \\
\hline BMI & & $59.83 \pm 11.5$ & $55.16 \pm 16.24$ & 0.393 \\
\hline $\begin{array}{c}\text { Mallampati } \\
\text { Score }\end{array}$ & I & $27.01 \pm 4.13$ & $26.45 \pm 2.47$ & 0.655 \\
\hline & II & $16.7 \%(\mathrm{n}=2)$ & $31.6 \%(\mathrm{n}=6)$ & \multirow{2}{*}{0.433} \\
\hline ASA class & I & $16.7 \%(\mathrm{n}=2)$ & $31.6 \%(\mathrm{n}=6)$ & \multirow{2}{*}{0.644} \\
\hline & II & $83.3 \%(\mathrm{n}=10)$ & $63.2 \%(\mathrm{n}=12)$ & \multirow{2}{*}{$0.68 .4 \%(\mathrm{n}=13)$} \\
\hline & III & 0 & $5.3 \%(\mathrm{n}=1)$ & \\
\hline
\end{tabular}

significant differences in sex, age, BMI, Mallampati score and ASA class between the groups (Table 1).

After 3 minutes, optimal preoxygenation was achieved in 17 of 31 patients $(54.8 \%)$, with success rates of $33.33 \%$ and $68.4 \%$ in groups A and $\mathrm{B}$ respectively $(\mathrm{p}=0.07)$. After 5 minutes, $\mathrm{EtO}_{2} \geq 90 \%$ was achieved in 22 of 31 patients $(70.97 \%)$, with the same success rate of $33.33 \%$ in group $A$ and $94.73 \%$ in group $B(p<0.001)$.

A comparison of mean $\mathrm{EtO}_{2}$ values at different durations of preoxygenation is shown in Table 1 . In addition to the markedly increased success rate, preoxygenation in group B was also faster and less variable: $228.33 \pm 104.03$ s vs. $164.37 \pm 84.31$ s to $\mathrm{EtO}_{2} \geq 90 \%$. A comparison of $\mathrm{EtO}_{2}$ values at different durations of preoxygenation is shown in Figure 1. EtO $\mathrm{E}_{2}$ was statistically significantly higher in group $\mathrm{B}$ after each 30 s interval ( $\mathrm{p}=0.006 ; 0.018 ; 0.034 ; 0.032 ; 0.01 ; 0.01 ; 0.006$; $0.003 ; 0.004 ; 0.004)$.

\section{Discussion}

We did not manage to find any other studies comparing different type anaesthesia face masks during preoxygenation. A study, conducted by Baillard, Depret, et al. which evaluates incidence and prediction of inadequate preoxygenation has some similarity [1]. This study enrolled 1050 patients undergoing general anaesthesia, excluding subjects with pulmonary comorbidities, trauma or shock. The authors observed an inadequate preoxygenation $\left(\mathrm{EtO}_{2}<90 \%\right.$ after 3 minutes) in $56 \%$ of the patients, while in our study the rate was $45.2 \%$ after 3 minutes. The higher rate of preoxygenation success in our study may be related with a face mask type used, smaller subject group and exclusion of patients with several risk factors for difficult face mask seal.

Taking a closer look into the conditions, necessary for effective preoxygenation, tight face mask seal is essential. There are a lot of possible factors predisposing air leakage, for example: inappropriate mask size, patient's obesity (BMI $>30$ ), toothlessness, patients snoring, lolly beard, inserted nasogastric tube, etc. [2,5,12]. We excluded patients with two or more risk factors mentioned previously. Baillard and colleagues claim that incomplete preoxygenation is also associated with patient gender (male have increased risk) and age (patients over 55 years old), ASA score of IV [2]. These kind of patients were not excluded so that the study subjects would represent a common population undergoing general anaesthesia for elective surgery. Comparing between the groups, our study showed that in the Economy mask group mean age was lower and in the QuadraLife group there were less males, but these deviations were statistically insignificant.

Another reason for the inward air leak is that patients may feel discomfort from having the anaesthetic face mask tightly applied onto the face, which could result in less pressure applied by the anaesthesiologist and reduced tightness of the mask [12]. We used Fentanyl (1-2 mcg/kg) to increase mask toleration and patient comfort. To reduce possible variations due to human factors, all the subjects were preoxygenated by a single anesthesiologist using classic EC clamp technique for holding of the face mask. There are some studies claiming that EO technique could provide a better mask seal, but the evidence is inconclusive $[13,14]$.

There is no uniform recommendation, concerning the fresh gas flow to be used for preoxygenation. Recently, some authors recommended using $100 \%$ oxygen with a high fresh gas flow set to $12-151 / \mathrm{min}[2,6,12]$. However, there are studies evaluating preoxygenation efficiency using oxygen flow as low as $5 \mathrm{l} / \mathrm{min}$ [15]. Lower oxygen concentration, which may result from lack of tight fit of the mask, rebreathing expired gas 
or an anaesthesia machine contour not primed with $100 \%$ oxygen, is associated with incomplete preoxygenation $[2,6,12]$. In our study we used $8 \mathrm{l} / \mathrm{min}$ flow and hypothetically sufficient preoxygenation rate could be higher with a higher flow. On the other hand, high oxygen flow may diminish the influence of inadequate face mask seal. Furthermore, higher oxygen flow needed for preoxygenation means higher expense for the institution and reducement of cost-effectiveness. Therefore, it is reasonable to investigate how to ensure fast and efficient preoxygenation while using less gas supply.

There is also an ongoing debate concerning optimal ventilation technique for preoxygenation. Most authors recommend the classic 3 min preoxygenation with patient breathing spontaneously as we did in the present study $[2,12]$, while others offer to use 8 deep breaths in 60 seconds technique $[6,16]$. The latter technique is used for a faster preoxygenation, usually before a rapid sequence induction. However, this method has limitation for obese or other risk group patients who cannot breathe deeply enough. A different approach is suggested by Hanouz, Jean-Luc, et al. They found that more efficient preoxygenation (decreased time to reached $\mathrm{EtO}_{2}$ at $90 \%$ ) is achieved with positive pressure support ventilation (PPV) with or without PEEP versus patients who were breathing spontaneously [17]. Meanwhile, Bignami, et al. in their systematic review suggest that PSV with PEEP allow for the fastest rise in $\mathrm{EtO}_{2}$ [18]. It would be reasonable to evaluate the performance of different type anaesthesia face masks in the light of these new ventilation strategies.

\section{Conclusion}

In our study new type of anaesthesia face mask (QuadraLite) performed better than the traditional cuffed anaesthesia face mask (Economy). QuadraLite allowed the desired $\mathrm{EtO}_{2}$ to be achieved faster and showed a higher optimal preoxygenation success rate. Further RCTs involving more subjects should be encouraged to obtain robust evidence.

\section{Institution of the study}

Center of Anaesthesiology, Intensive Care and Pain Treatment of Vilnius University Hospital Santaros Clinics, Vilnius, Lithuania.

\section{References}

1. Baillard C, Depret F, Levy V, Boubaya M, Beloucif S (2014) Incidence and prediction of inadequate preoxygenation before induction of anaesthesia. Ann Fr Anesth Reanim 33: e55-58. [Crossref]
2. Xu Z, Ma W, Hester DL, Jiang Y (2017) Anticipated and unanticipated difficult airway management: Current Opinion in Anaesthesiology 31: 96-103.

3. Cook TM, MacDougall-Davis SR (2012) Complications and failure of airway management. Br J Anaesth 109 Suppl 1: i68-68i85. [Crossref]

4. De Jong A, Futier E, Millot A, Coisel Y, Jung B, et al. (2014) How to preoxygenate in operative room: healthy subjects and situations "at risk". Ann Fr Anesth Reanim 33 457-461. [Crossref]

5. Bouroche G, Bourgain JL (2015) Preoxygenation and general anesthesia: a review. Minerva Anestesiol 81: 910-920. [Crossref]

6. Tanoubi I, Drolet P, Donati F (2009) Optimizing preoxygenation in adults. Can J Anaesth 56: 449-466. [Crossref]

7. Berry CB, Myles PS (1994) Preoxygenation in healthy volunteers: a graph of oxygen "washin" using end-tidal oxygraphy. British Journal of Anaesthesia 72: 116-118.

8. McGowan P, Skinner A (1995) Preoxygenation--the importance of a good face mask seal. Br J Anaesth 75: 777-778. [Crossref]

9. https://www.intersurgical.com/products/anaesthesia/quadralite-anaesthetic-face-mask

10. Samsoon GL, Young JR (1987) Difficult tracheal intubation: a retrospective study. Anaesthesia 42: 487-490. [Crossref]

11. https://www.intersurgical.com/products/anaesthesia/economy-anaesthetic-face-masks

12. Hanouz JL, Le Gall F, Gérard JL, Terzi N, Normand H (2018) Non-invasive positivepressure ventilation with positive end-expiratory pressure counteracts inward air leaks during preoxygenation: a randomised crossover controlled study in healthy volunteers. British Journal of Anaesthesia 120: 868-873.

13. Umesh G, Krishna R, Chaudhuri S, Tim TJ, Shwethapriya R (2014) E-O technique is superior to $\mathrm{E}-\mathrm{C}$ technique in manikins during single person bag mask ventilation performed by novices. J Clin Monit Comput 28: 269-273. [Crossref]

14. Umesh G, Gotur GV, Rao AK, Joseph TT (2018) EO technique provides better mask seal than the EC clamp technique during single handed mask holding by novices in anaesthetised and paralysed patients. Indian J Anaesth 62: 780-785.

15. Baraka AS, Taha SK, Aouad MT, El-Khatib MF, Kawkabani NI (1999) Preoxygenation: comparison of maximal breathing and tidal volume breathing techniques. Anesthesiology 91: 612-616.

16. Nimmagadda U, Chiravuri SD, Salem MR, Joseph NJ, Wafai Y, et al. (2001) Preoxygenation with tidal volume and deep breathing techniques: the impact of duration of breathing and fresh gas flow. Anesth Analg 92: 1337-1341. [Crossref]

17. Hanouz JL, Lammens S, Tasle M, Lesage A, Gérard JL, et al. (2015) Preoxygenation by spontaneous breathing or noninvasive positive pressure ventilation with and without positive end-expiratory pressure: A randomised controlled trial. Eur J Anaesthesiol 32: 881-887.

18. Bignami E, Saglietti F, Girombelli A, Briolini A, Bove T, et al. (2019) Preoxygenation during induction of anesthesia in non-critically ill patients: A systematic review. J Clin Anesth 52: 85-90.

Copyright: (C)2019 Kontrimavičiūtė E. This is an open-access article distributed under the terms of the Creative Commons Attribution License, which permits unrestricted use, distribution, and reproduction in any medium, provided the original author and source are credited. 